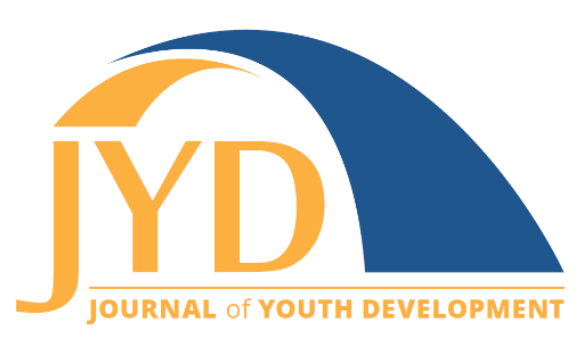

http://jyd.pitt.edu/ | Vol. 12 Issue 1 DOI 10.5195/jyd.2017.491 | ISSN 2325-4017 (online)

\title{
Investing in Youth Work: Learning from Complexity
}

\author{
Kari Denissen Cunnien \\ Ignite Afterschool \\ Minnesota's Afterschool Network \\ kari@igniteafterschool.org
}

\begin{abstract}
This article proposes key elements for a system of support for youth workers to develop their professional skills and capabilities by using a human development approach. The article argues that narrowed and bureaucratic approaches to professional development can ignore the complex dynamics of human development that support engaged learning and continuous growth and improvement. The author suggests a more dynamic system where professional development in grounded by practice; employs reflection, mentorship and coaching; and supports healthy organizational culture to foster high quality youth work.
\end{abstract}

Today there is a new theoretical paradigm in the development and policy world. Known as the "Human Development" approach, and also as the "Capability Approach" or "Capabilities Approach," it begins with a very simple question: What are people actually able to do and to be? What real opportunities are available to them? This question, though simple, is also complex, since the quality of a human life involves multiple elements whose relationship to one another needs close study. Indeed, one of the appealing features of the new approach is its complexity: it appears well equipped to respond to the complexities of human life and human striving.

(Nussbaum, 2011, p.x)

\section{The Context}

Nationally, the achievement gap between Black, Hispanic and White students continues to persist. While all students, including Black and Hispanic students, have improved since the

(cc) EY New articles in this journal are licensed under a Creative Commons Attribution 4.0 License. This journal is published by the University Library System, University of Pittsburgh and is cosponsored by the University of Pittsburgh Press. The Journal of Youth Development is the official peer-reviewed publication of the National Association of Extension 4-H Agents and the National AfterSchool Association. 
early years of the National Assessment of Educational Progress (NAEP) in 1990, the gap between White students and students of color remains significant with gaps between 21 and 26 points depending on grade and subject area (Vanneman, Hamilton, Anderson, \& Rahman, 2009). One of the deepest race-based achievement gaps in the country is in Minnesota, which is the context for this article's research. Ensuring educational equity and seeking strategies that will close the gap is both a social justice challenge and economic imperative that permeates our public discourse both nationally and in local communities.

Many of the solutions recently employed to fix the achievement gap place value on a strategyalignment (and often focus-narrowing) approach. Under President Obama, the federal government encouraged reform through competitive state grants like Race to the Top, and national service programs like VISTA, intended to address poverty, often directed by state agencies to narrow focus on specific strategies like reading interventions. Meanwhile, following calls for alignment, local funders shift priorities to address clear academic outcomes like reading by third grade and communities set their sights on replicating programs like the Harlem Children's Zone and Cincinnati Strive, two place-based initiatives that have gained national attention for their unrelenting focus on strategy alignment around academic outcomes.

Nobel Prize winning economist James Heckman's work complicates our understanding of what makes a young person successful. In his study on the effectiveness and impacts of the General Educational Development (GED), he found that mastering high school level content alone does not guarantee young people's future success. Equally important-and maybe even a prerequisite for mastering content in a school or community setting-are a cluster of skills like curiosity and "stick-to-itiveness" (Heckman, James, \& Rubinstein, 2001). Whether you call them, character traits, social emotional competencies, or $21^{\text {st }}$ century skills, they are making a comeback with state education agencies, nonprofits, and national funders who are beginning to develop social emotional learning frameworks. These types of skills can be complicated to define and difficult to measure. Many argue it is easy to hold someone accountable to making sure a child can read, but to hold them accountable for making sure a child is curious? There is robust debate underway about the appropriateness of tying accountability measurements to young people's social and emotional development with organizations like the American Institutes of Research (2015) encouraging all of us to stop and think before we act.

This is the milieu of ideas, debate and conversation that dominate the formal education and after-school landscape. Another place-based initiative, Sprockets, brings together large systems 
like the school district and city government with community organizations to improve the quality, availability and effectiveness of out-of-school time learning for all youth in Saint Paul, Minnesota. In this work, the focus is on learning outside the classroom and is most often done by youth workers who work alongside young people. What becomes complicated for all involved in this effort is clarity in understanding what youth workers are ultimately responsible for in their work with youth. Is it academic success? Social and emotional competencies? Both? Or something else all altogether?

As I talk to colleagues nationally and read literature in the youth work field, I am aware of the systems-level conversations and tangible work happening across the country to credential youth workers. Credentialing is viewed as a strategy to ensure the quality of out-of-school learning opportunities and to ensure youth workers are accountable to an agreed upon set of youth worker competencies. Often it is also argued that credentialing and/or licensing youth workers will improve the status, pay and work experience of youth workers. These days, however, the language of high expectations and accountability is fully loaded and often feels blaming and divorced from creating authentic spaces for learning and development-of youth or the people who work with them.

For the purposes of this article, I focus on youth workers' accountability to themselves and to the young people they work with. I want to ensure that a system of support for youth workers is less about compliance and more about supporting youth workers to develop their capabilities to grow as practitioners so they can create more powerful, meaningful and high quality experiences with and for young people. Instead of imagining creative systems and then asking what impact each of those systems would have on youth work, I explore what youth workers want and what type of system they feel would best achieve those goals.

Ultimately, I propose key elements for a system of support for youth workers to develop their professional skills and capabilities, however, I must first define what I believe the role and goal of youth work is in communities. It is because of the swirling, often contradictory, public discourse about young people and what they need that I find it important to take a stance on what youth work is and what youth workers should be accountable for. Second, I will explore the national conversation and efforts around credentialing as it relates to creating systems of support for youth work. Lastly, I will describe conversations with youth workers around this topic and share proposed elements of a system of support informed by their perspectives. 


\section{Defining Youth Work}

There is disagreement among people who work with youth outside of formal school settings about who youth workers are and are not. Youth workers can be found working with young people in recreation centers, schools, community centers and faith-based settings. They facilitate after-school and youth groups, sports teams and a range of other after-school and summer learning opportunities where young people have choice in their participation. They work with young people from a variety of backgrounds: from more stable home environments to youth experiencing significant stresses related to poverty or other community and family instabilities. While many would include staff in youth detention or residential treatment centers in their definition of youth workers, they are outside the scope of my definition as young people typically do not have choice in their participation and I do not include therapy in my definition of youth work.

To get outside the debate about where youth work happens or does not happen, I find it more useful to describe youth workers, not by the setting in which they work, but by the approach and core values that guide their practice. I like the definition that came out of a 2004 Wingspread Conference where youth workers are defined as "individuals who work with or on behalf of youth to facilitate their personal, social and/or educational development and enable them to gain voice, influence, and place in society as they make the transition from dependence to independence" (Stone, Garza, \& Borden, 2004, p. 9).

Youth work is about supporting holistic human development-the subject matter content is often secondary. This concept is even more critical given the social and political context described earlier that is pushing youth workers to be less focused on the whole child and to have a more myopic focus on young people's academic success. Supporting young people's identity as a student is one part of the youth work definition, but it is far from all of it. If we are going to talk about holding youth workers accountable, it is critical to put a stake in the ground and be unwavering in our clarity that youth work is about human development, inclusive of but not exclusive to supporting young people's academic achievement.

\section{Credentialing Youth Workers}

To begin my exploration of systems of support for youth workers, I wanted to know more about what credentialing advocates feel is promising and necessary about credentialing. An article reviewing professional credentials in out-of-school time defines a credential as, "a certification 
that recognizes an individual's performance based on a set of defined skills and knowledge" (Dennehy, Gannett, \& Robbins, 2006, p. 9). In 2008, the Academy for Educational Development's (AED) Center for Youth Development brought sixteen leaders in the youth work field together to discuss the state of the field. A summary report based on the convening envisions "a day soon when all youth workers in the United States are fully trained and certified" (AED, 2008, p.4). The reasons provided for moving toward this goal are not simply laid out and they range from ensuring youth work has the same professional integrity as teaching and social work to an argument that youth workers will not succeed in teaching lifelong skills and competencies for the success of youth if they are poorly prepared and lack support (AED, 2008).

Many advocates of credentialing for youth workers cite studies-largely in early childhood education and school-based teaching-that show practitioner education, professional development and training to be key factors in producing quality outcomes for youth (Curry, Schneider-Muñoz, Eckles, and Stuart, 2012; Dennehy, Gannett, \& Robbins, 2006). Professional development and training and credentialing are not synonymous, and what remains unclear is how these findings lead to the conclusion that credentialing and/or licensing is key to a system of support for youth workers.

Despite the growth in professional development programs, there have been few formal scientific evaluations to measure their [credentials'] success. However, there has been a tremendous amount of research in both the out-of-school time (OST) and early care and education (ECE) fields demonstrating that more highly educated staff provide higher quality services to children and youth and promote healthier working environments.

(Dennehy, Gannett, and Robbins, 2006, p. 10)

While checklists can simplify the complexity, we must be careful not to lull ourselves into the belief that attending a training aligned with each competency and walking away with a credential will, on its own, lead to better youth work.

\section{Listening to Youth Workers: Perspectives on Credentialing or Licensing}

Through two listening sessions, I spoke with 17 youth workers and youth program managers connected to Sprockets, the out-of-school-time network in Saint Paul, Minnesota. All but two (or $88 \%$ ) of participants self-identified as youth workers; $88 \%$ also reported working directly with youth at least some of time. The two who did not work with youth at least some of the time act 
as youth program managers. Of the 15 who work with youth at least some of the time, about half do direct youth work only, while the other half do direct youth work and act as a youth program manager. All 17 listening session participants had completed some form of higher education. One (6\%) had an associate degree, $11(67 \%)$ had a bachelor's degree and five (29\%) had an advanced degree. I did not request information on the topic area of degrees and am not able to report how many had a youth work, education, or youth development-related degree.

During listening sessions, participants were first asked to share their initial reactions and assumptions about youth worker licensure and/or credentialing (free association brainstorm). Their reactions to the concept were then further discussed and "unpacked." Next, they were asked to share what they believe a creative system of accountability and expectations for youth workers should look like. As youth workers talked about credentialing and/or licensing youth workers, three clear themes emerged. No matter what question was posed, the groups always wove their way back to the following points:

1. Racial equity: It was feared that credentialing or licensing (these terms were used interchangeably by youth workers in listening sessions) would lead to a "whitening" of the field and that youth workers of color and/or from low-income backgrounds would have significantly greater access barriers to the field than white and/or higher-income individuals. Most felt this would not benefit young people in diverse communities because they would find fewer and fewer youth workers who look like them.

2. Youth work is not a $100 \%$ learned craft. Many believe that truly good youth workers bring something intrinsic to the table that can't be taught; that a youth worker is something more akin to an artist. Artists can get better through training, education, practice and mentorship but if you're not an artist, you're not an artist. The youth workers I talked with felt the same holds true in their line of work. Training can help a youth worker improve at his/her craft, but some folks, no matter how much training they receive, just aren't youth workers. They did not believe that credentialing and/or licensure in any way will guarantee good youth work. They believe it is the responsibility of good youth program managers to recognize a talented youth worker when hiring.

3. Licensure does not necessarily mean better pay. Youth workers were clear that they want better pay and benefits. They argued that youth workers are generally young because they have to move on to other positions in order to attain other life goals like 
having a family or buying a home. Youth workers noted that this also means that just when they feel experienced in their work, they can no longer sustain a direct youth work career. Most of the youth workers I talked to were very suspicious of any assertion that licensing or credentialing will lead to better pay. When someone suggested that teachers are better paid because of licensure another responded it's more likely because of teacher unions. Another participant was not convinced that the private philanthropic or public funding sources for youth programs would have any interest in supporting higher salary lines in grant applications but would probably still expect a credential and higher outcomes anyway. For the most part, they felt that efforts to create credentials may be about improving quality and raising accountability, but that paying more for it was not a part of most decision-maker's conversations.

In 2005, the Next Generation Youth Work Coalition (Next Gen) commissioned the Forum for Youth Investment to conduct a survey of 1,053 youth workers, 195 organization directors and focus groups with 70 youth workers across eight cities (Yohalem, Pittman, \& Moore, 2006). The goal was to better understand who youth workers are and the conditions of their work. The Forum produced a report that is considered one of the best views of youth workers we have; it included information from this study alongside a survey of youth workers conducted by the National Afterschool Association. The youth workers surveyed were a diverse lot. While primarily under age 30, a good number were in their 40 s and 50 s. The majority of youth workers surveyed were people of color and had some post-secondary education: $60 \%$ had a 2 year degree or higher while two thirds had a relevant credential. While the sampling used in the study does not allow for the results to be generalized to youth workers more broadly, the study still tells us some important things and gives some credibility to the perspectives of youth workers I spoke with in Saint Paul.

Some findings around youth workers' salary and education were particularly relevant. While the median salary was between $\$ 25,000$ and $\$ 25,999$ (less as an hourly rate for part-time staff), those with two or more years of post-secondary education were more likely to be white with a social work or education credential (as opposed to a youth work or youth development credential), were paid more and were more likely to say that their background is different than the youth they work with (p. 29). The lower-paid, often part-time staff was more likely to comprise people of color who had a youth work credential such as completion of the Advancing Youth Development (AYD) program. These youth workers were more likely to say that their background was similar to the youth they work with. 
Yohalem, Pittman, and Moore's (2006) findings seem to reinforce the fears of the youth workers' I interviewed. Better-paid youth workers were better educated and more likely to be white-lacking a background reflective of the youth they worked with. These findings reiterate, to me, that unless implemented in a very creative and non-traditional way, credentialing systems could exacerbate this reality. Another area of interest is that the youth workers who actually had a youth work credential (as opposed to the related, but different, fields of social work and education) were less well paid. This could be due to the fact that there is not one standard, agreed-upon system of credentialing for youth workers as there is for social work or education, but I question whether having a common approach would actually lead to higher pay.

Another finding from Yohalem, Pittman and Moore (2006) is worth noting. When asked what they think would most help advance the profession, both youth workers and program directors said raising wages and increasing program resources, in that order, over things like professional development and minimum credentials. This aligns very nicely with what the youth workers I spoke with said. So the question becomes: why are we asking about creative accountability and expectation systems instead of asking what we can do to make youth work an actual, viable profession? The youth workers I spoke with did value conversations about professional development, but its value was as an opportunity to improve their practice rather than as a strategy to gain higher pay.

\section{Crafting a System to Support Youth Wok Practice}

Whether someone is a proponent of credentialing or not, my research and conversations found that most agree that a creative system of supports for youth workers must have multiple elements. In this section I lay out the elements and characteristics of a system of youth work support that I've come to believe are important. In my conversations with youth workers, many elements of a creative system were identified. Themes from the listening sessions deeply influenced my final thinking and I do my best here to represent the ideas from those listening sessions. In addition, my final conclusions are influenced by readings, discussions with colleagues, as well as my own experience as both a frontline youth worker and director of an out-of-school-time intermediary network in the early stages of developing a system of supports for youth workers. 


\section{Dynamic System}

In my professional work in afterschool systems-building, we talk a lot about continuous quality improvement. What we mean is that quality never reaches stasis. Achieving quality is much more like growing a garden; you never reach a point where your final product no longer requires weeding, fertilizing, or tending. In order to maintain your garden, constant tending that accounts for changes in the environment is necessary. This is the first critical element for any system; it can never become static. Instead, a creative system of support for youth workers must be constantly attended to in order to ensure it remains relevant and is achieving its stated purpose. This does not mean that offering trainings every year alone ensures the system is not static; it means that there must be constant attention to youth workers' engagement in their learning and development within the system.

The youth workers I spoke with also identified this element and added that it is youth workers who must be on the team of "tenders." They warned against external sources of authority managing a system to support youth workers who are too far away from the day-to-day realities of direct youth work practice or who have competing interests and motivations. Part of the tending must also be to ensure that there remain multiple points of entry into the field, and to guard against standardization so that youth work continues to be a field accessible to people from diverse backgrounds and experiences. The system should never require every youth worker to gain a degree, license or credential that is exclusionary due cost or initial acceptance or entry (into a higher education institution). The system should be outside of formal higher education systems but could include higher education options for those interested.

\section{Professional Development}

The types of learning opportunities and experiences that should be available within the system are the next elements to consider. First, professional development opportunities must be grounded in practice. Therefore, youth workers should have formal opportunities to reflect on their experiences in doing youth work. This is key to much of what Walker and Walker (2012) propose about youth workers building judgment. Youth workers need opportunities to talk with other youth workers about challenges and successes in a way that pulls those experiences apart and makes them "learning cases." Related to this (or one example of it) is youth workers' need for opportunities for apprenticeship and mentorship from those with more practice experience. It is possible that youth workers receive mentorship by program managers or others within their organization but many youth workers in the two listening sessions suggested that a more structured and formal mentorship or apprenticeship system would be valuable. 
Youth workers do believe that trainings such as classes, workshops, one-time sessions and conferences must also be part of the professional development components. These provide important venues to learn key youth work concepts and skills. They did not feel that these, in and of themselves, are adequate but that strong mentorship with opportunities for reflection are what make trainings meaningful and able to be tied to daily practice.

\section{Organizational Health}

Lastly, there are things that can be done to strengthen the ecology of youth work. Investments made in workers in the "middle" of organizations could help because these are the supervisors, managers and organizational leaders who are responsible to support the frontline, direct-service youth workers. A few youth workers who participated in the listening sessions made the interesting assertion that, if an investment is going to be made in a credentialing or licensing structure, it is program managers and not frontline youth workers who should be required to have a credential.

It is critical to recognize that youth workers and the quality of their practice do not happen in isolation from the environment in which they work. The health and wellness of the organizations offering youth learning opportunities can greatly impact the ability for youth workers to practice effective youth work. Any system must also provide opportunities to address the capacity of organizations to ensure opportunities for reflective practice and that leaders in the organization also understand the key aims, skills, knowledge and experiences that lead to improved youth work.

While the focus of this paper was not explicitly to address pay and advancement opportunities for youth workers, I feel it would be too big an omission not to address compensation at all. Youth workers did feel that quality youth work is also tied to experience and that low pay and unclear opportunities for advancement make it difficult to remain in direct youth work once they become experienced. I agree with the youth workers I spoke with that these issues are related to systems that support quality youth work but that these issues cannot be solely addressed by creating professional development systems. They are influenced by political environments, funding streams and other factors that also need to be addressed in order to achieve adequate pay and advancement opportunities for youth workers. This is a topic that deserves more exploration and attention than could be given in this article. 


\section{Conclusion}

While simple answers are generally preferred, crafting systems to support youth work practice is a complicated task. It is complicated by the push and pull of public discourse about what the role and ultimate impact of out-of-school time should be. I argued that it is critical for youth workers to claim their work as human development, inclusive of but not exclusive to academic success. Even with this clarity, complexity remains. Human development is complex-both the work to support youth in growing their capabilities and the work of youth workers to develop their practice. Also, understanding and agreeing upon the elements of quality youth work practice is complex. Are competencies enough or is there something more nuanced that lives in the grey areas of human experience that requires youth workers to build judgment that is situational and can only be nurtured through reflection and mentorship, rather than competency trainings and exams?

Lastly, crafting the system itself is complex. It requires constant tending, multiple entry points and multiple types of professional development opportunities. It also requires attention not just to youth workers but to the organizations and settings in which they work. Yet complexity should not lead to our paralysis. As Martha Nussbaum (2011) argues in the opening quotation, one of the appealing features of the human development approach is its complexity because it is the only approach able to respond to the complexities of deciding who to be and what to do. While complex, the elements described above are possible and can be realized by engaging networks of youth workers and related stakeholders as the experts of their domain.

\section{References}

AED. (2008). Youth work: Organizing pathways for leadership development and social change. Highlights from Youth Worker Training and Certification Summit Meeting, October 2008.

American Institute of Research. (2015). Are you ready to assess social and emotional development? (Brief.) Retrieved from http://www.air.org/sites/default/files/AIR\%20Ready\%20to\%20Assess_STOP.pdf

Curry D., Schneider-Muñoz, A., Eckles,F., \& Stuart, C. (2012). Assessing youth worker competence: National child and youth worker certification. In D. Fusco (Ed.), Advancing youth work: Current trends, critical questions (pp. 27-38). New York, NY: Routledge. 
Dennehy, J., Gannett, E, \& Robbins, R. (2006). Setting the stage for a youth development associate credential: A national review of professional credentials for the out-of-school time workforce. Houston, TX: Cornerstone for Kids.

Heckman, James, J. \& Rubinstein, Y. (2001). The importance of noncognitive skills: Lessons from the GED testing program. American Economic Review, 91(2): 145-149.

Nussbaum, M. (2011). Creating capabilities: The human development approach. Cambridge, MA: Harvard University Press.

Stone, B., Garza, P., \& Borden, L. (2004). Attracting, developing \& retaining youth workers for the next generation. Wingspread conference proceedings, November 16-18, 2004. Retrieved from https://cyfar.org/sites/default/files/Stone\%202004.pdf

Vanneman, A., Hamilton, L., Baldwin Anderson, J., \& Rahman, T. (2009). Achievement gaps: How black and white students in public schools perform in mathematics and reading on the National Assessment of Educational Progress (NCES 2009-455). Washington, DC: National Center for Education Statistics, Institute of Education Sciences, U.S. Department of Education.

Walker, J., \& Walker, K. (2012). Establishing expertise in an emerging field. In D. Fusco (Ed.), Advancing youth work: Current trends, critical questions (pp. 39-51). New York, NY: Routledge.

Yohalem, N., Pittman, K., \& Moore, D. (2006). Growing the next generation of youth work professionals: Workforce opportunities and challenges. Houston, TX: Cornerstones for Kids. 